九州大学学術情報リポジトリ

Kyushu University Institutional Repository

\title{
Production of Female Bovine Embryos with Sperm Sorted by Magnetic Activated Cell Sorting
}

\section{ZHUANG, Li Li}

Division of Animal and Dairy Science, College of Agriculture and Life Science, Chungnam National University | Life science and technology school, Shanghaitech University

CHUN, Ju Lan

Division of Animal and Dairy Science, College of Agriculture and Life Science, Chungnam National University

WU, Junbo

Division of Animal and Dairy Science, College of Agriculture and Life Science, Chungnam National University | Life science and technology school, Shanghaitech University

\section{LEE, Ji Hye}

Division of Animal and Dairy Science, College of Agriculture and Life Science, Chungnam National University

他

https://doi.org/10.5109/1909901

出版情報: 九州大学大学院農学研究院紀要. 63 (1)，pp.45-52，2018-02-27. Faculty of Agriculture， Kyushu University

バージョン：

権利関係 : 


\title{
Production of Female Bovine Embryos with Sperm Sorted by Magnetic Activated Cell Sorting
}

\section{Lili ZHUANG ${ }^{1,2 * *}$, Ju Lan CHUN ${ }^{1 * *}$, Junbo WU ${ }^{1,2}$, Ji Hye LEE $^{1}$, Eun Young KIM ${ }^{1}$, Bo Myoung LEE ${ }^{1}$, Nobuhiko YAMAUCHI ${ }^{3}$, Hyung Suk LEE ${ }^{4}$ and Min Kyu KIM ${ }^{1 *}$}

\author{
${ }^{1}$ Division of Animal and Dairy Science, College of Agriculture and Life Science, Chungnam National University, \\ 220 Gung-dong, Yuseong-gu, Daejeon 305-764, Republic of Korea \\ ${ }^{2}$ Life science and technology school, Shanghaitech University, 230 Haike Road, Shanghai, China \\ ${ }^{3}$ Deptment of Animal and Marine Bioresource Science, Faculty of Agriculture, Kyushu University, Fukuoka, Japan \\ ${ }^{4}$ Division of Companion Animal Science, Woosong College, Daejeon, 34518 \\ (Received October 19, 2017 and accepted November 20, 2017)
}

\begin{abstract}
Sperm sexing is an efficient mean to obtain offspring with desired male and female. For sexing bovine sperm, flow cytometry has been used as a practical method. However, sperm sorting equipments are fairly expensive and complicated. Recently magnetic activated cell sorting (MACS) has been widely applied in reproductive researches because it is a relatively simple and less time consuming technique. In this study MACS was thereby performed to enrich the X-chromosome bearing sperm and to produce female bovine embryos. The sorting efficiency of MACS was calculated by fluorescence activated cell sorting (FACS). The motility of sorted X-chromosome bearing sperm was evaluated by computer-assisted analysis (CASA) prior to using them for fertilization of oocytes, and then the quality and sex of embryos were evaluated. The X-chromosome bearing sperms were significantly enriched after MACS. Sperms maintained their fertility after the MACS sorting. Curvilinear velocity (VCL), straight-line velocity (VSL), average path velocity (VAP), beat cross-frequency (BCF), amplitude of lateral head displacement (ALH) and linearity (LIN) were not dramatically decreased, but motility (MOT), mean angular displacement (MAD) and straightness of path (STR) were significantly reduced. Although the embryos derived from sorted X-chromosome bearing sperm showed decreased rates of cleavage and blastocyst formation compared to those of embryos with non-sorted sperm, there was no significant difference between embryos generated with unsorted and sorted sperm in terms of the quality of embryos. Moreover the number of female embryos was significantly increased after MACS. In conclusion, MACS effectively enriched the X-chromosome bearing sperms and produced female bovine embryos without deterioration of embryo quality. Therefore MACS is a feasible technique to sort targeted gender of sperm especially X-chromosome bearing sperm that would contribute to reducing the cost of maintaining animals of the undesired sex or to optimize numbers of animals of the desired sex in the livestock industry.
\end{abstract}

Key words: Bovine, Embryo, in vitro Fertilization, Magnetic Activated Cell Sorting, Sexing

\section{INTRODUCTION}

Assisted reproductive techniques (ART) have been applied in the last decade (Said et al., 2008). Sperm sexing is a practical ART which allows pre-selecting the sex of offspring to produce the optimal proportions of males and females to take advantage of sex-limited and sex-influenced traits (Johnson et al., 2000; Rath et al., 2008). For example, female bovines are useful to produce dairy products and calves, while male bovines with high genetic merit are invaluable as sires in reproductive improvement programs (Espinosa-Cervantes et al., 2013). One of the most effective methods to produce sex predetermined offspring is to use sex separated sperm in conjunction with other reproductive techniques including artificial insemination (AI), in vitro fertilization (IVF), intracytoplasmic sperm injection (ICSI) and embryo transfer (ET).

* Corresponding author: Min Kyu Kim, DVM, Ph. D; Address: 99 Daehak-ro (st), Yuseong-gu, Daejeon, 305-764, Republic of Korea, E-mail: kminkyu@cnu.ac.kr; Tel: +82-42-821-5773; Fax: +82-42-825-9754.

** Lili Zhuang and Ju Lan Chun have contributed equally to this work.
Several techniques have been attempted to separate $\mathrm{X}$ - and $\mathrm{Y}$-chromosome bearing sperm based on different parameters like mass and motility, swimming patterns, surface changes, centrifugal countercurrent distribution, and immunologically relevant properties (Peter et al., 1970; Ericsson et al., 1973; Jain et al., 2011). Among them flow cytometry has been a routine procedure for practical applications in the bovine sperm sexing (Espinosa-Cervantes et al., 2013; Maxwell et al., 2004). However sperm sexing equipment is fairly expensive and is more than $\$ 350,000$ per sperm sorter. Skilled operators are also required to install and maintain the relatively complicated sperm sexing equipment and procedures (Seidel et al., 2007). The most serious problem of flow cytometry is the increased possibility of deteriorating sperm due to the chemical and mechanical stress of the sorting procedure that results in increased dead or damaged sperm by 18.6\% (Espinosa-Cervantes et al., 2013) and dramatically reduced sperm motility patterns (Blondin et al., 2009). Therefore, it is very meaningful to establish an efficient, less expensive approach for sexing mammalian sperms.

Magnetic activated cell sorting (MACS) has been used in the ART because it is readily available and relatively inexpensive (Said et al., 2008). MACS is the one 
of preparation techniques that yields motile, viable, morphologically normal spermatozoa which have higher fertilization potential (Aziz et al., 2007). MACS uses a specific antibody conjugated magnetic microspheres which bind to a target antigen or protein so that different cell fractions could be separated by exposing the combined populations to a magnetic field in an affinity column (Gil et al., 2013). For example, annexin V conjugated magnetic microspheres could be used to separate apoptotic from non-apoptotic sperm (Vermes et al., 2005). Base on those advantages, MACS could be used in sperm sexing to efficiently generate fertile sperm.

Antibodies against $\mathrm{H}-\mathrm{Y}$ antigen were firstly reported in 1971 (Goldberg et al., 1971). It has been suggested that the expression of $\mathrm{H}-\mathrm{Y}$ antigen was restricted to $\mathrm{Y}-$ chromosome bearing sperm (Bennett et al., 1973; Zavos et al., 1983; Ali et al., 1990). Peter et al. developed an immune-magnetic method to separate out bull sperm which are bound with the antibody targeting $\mathrm{H}-\mathrm{Y}$ IgG assuming that only $\mathrm{Y}$ chromosome-bearing sperm have $\mathrm{H}-\mathrm{Y}$ antigen on the cell surface (Peter et al., 1993). Even though the results suggested that the immune-magnetic method could be a feasible method to select/remove the Y-chromosome bearing sperm, it is still controversial whether the immune-magnetic method using $\mathrm{H}-\mathrm{Y}$ antigen is sufficient to sort sperm and to produce specified sex of embryos with those sperm (Hendriksen et al., 1993).

This study aimed to enrich pre-selected X-chromosome bearing sperm by removing $\mathrm{H}-\mathrm{Y}$ antigen expressing Y-chromosome bearing sperm using MACS. Furthermore the sterility of pre-selected X-chromosome bearing sperm was verified when female cattle embryos were successfully produced with the enriched $\mathrm{X}$-chromosome bearing sperm using IVF.

\section{MATERIALS AND METHODS}

All chemicals were purchased from Sigma-Aldrich Chemical Company (St Louis, MO) unless otherwise stated.

\section{Preparation of the antibody against $\mathrm{H}-\mathrm{Y}$ antigen}

For producing $\mathrm{H}-\mathrm{Y}$ antibody to detect $\mathrm{Y}-$ chromosome bearing bovine sperms the anti-H-Y monoclonal antibody 12/49 (Moab 12/49) producing hybridoma cells (HB-9071) were purchased from American Type Culture Collection (ATCC). The hybridoma clones were grown in RPMI1640 medium (ATCC) supplemented with 10\% fetal bovine serum (FBS, Gibco) under the culture conditions provided by the company. After a gradual decrease in the percentage of FBS, the culture medium for hybridoma clones was replaced by serum-free medium (Gibco, cat. No. 12045-084) prior to harvesting the Moab from the culture medium. The Moab in media was concentrated 10 - to 20-fold by Amicon filtration (Merck Millipore), aliquoted, and frozen at $-80^{\circ} \mathrm{C}$ until use. The concentration of $\mathrm{H}-\mathrm{Y}$ monoclonal antibody was determined by sandwich ELISA according to the instructions of Mouse IgM ELISA kit (Abcam).

\section{Separation of $\mathrm{X}$ - and $\mathrm{Y}$-chromosome bearing sperm by MACS}

Frozen semen straws were thawed in a water bath at $37^{\circ} \mathrm{C}$ for $60 \mathrm{~s}$, suspended with MACS buffer (Miltenyi Biotec), and centrifuged at $500 \times \mathrm{g}$ for $5 \mathrm{~min}$. The washing procedure was repeated 3 times. After the final washing, the sperm pellet was resuspended in MACS buffer, and the concentration of sperm was determined using a hemacytometer. For MACS sperm were suspended in $200 \mu \mathrm{L}$ MACS buffer, and then incubated with $100 \mu \mathrm{L}$ of Moab 12/49 for $1.5 \mathrm{~h}$ at room temperature with gentle vortexing every $30 \mathrm{~min}$. Following the incubation, the sperm were washed with $2 \mathrm{~mL}$ MACS buffer, and centrifuged at $500 \times \mathrm{g}$ for $5 \mathrm{~min}$. $20 \mu \mathrm{L}$ of anti-mouse IgM MicroBeads (Miltenyi Biotec) was added to the resuspended sperm pellet at the density of $10^{7}$ cells, and incubated for $15 \mathrm{~min}$ at $2-8^{\circ} \mathrm{C}$. The sperm were washed by adding $1-2 \mathrm{~mL}$ of buffer, and centrifuged at $500 \times \mathrm{g}$ for $5 \mathrm{~min}$. Resuspended sperm in $500 \mu \mathrm{L}$ of buffer were subjected to magnetic separation on the LD column (Miltenyi Biotec).

The sperm in the flow-through fluid were collected, and used to fertilize bovine oocytes in vitro, and labeled "sorted". Sperm without MACS sorting were labeled "unsorted".

\section{Fluorescence activated cell sorting (FACS) analy- sis of sperm}

In order to determine the rates of $\mathrm{X}$-chromosome sperm after MACS rabbit anti-bovine SRY polyclonal antibody (MyBioSource) were used. Briefly, unsorted and sorted sperm were fixed with $4 \%$ paraformaldehyde in PBS-PVA for $1 \mathrm{~h}$, and permeabilized with $0.5 \%$ Triton $\mathrm{X}-100$ in PBS-PVA for $30 \mathrm{~min}$ at room temperature. Sperm were blocked with PBS containing 10\% BSA, and incubated with rabbit anti-bovine SRY polyclonal antibody (1:10 in PBS) or Moab 12/49 overnight at $4^{\circ} \mathrm{C}$. Sperm were then stained with TRITC conjugated goat anti-rabbit IgG secondary antibody (MyBioSource) (1:64 in PBS) or anti-mouse IgM FITC antibody (Miltenyi Biotec) (1:10 in MACS buffer) for $15 \mathrm{~min}$ at $4^{\circ} \mathrm{C}$, respectively. Sperm, which were only treated with BSA for blocking, were used as negative controls. Fluorescence was detected by flow cytometry (Becton Dickinson), and the results were analyzed by FlowJo 7.6.1 software program.

\section{Computer-Assisted Sperm Analysis (CASA)}

The total motility of both unsorted and sorted sperm was assessed by using CASA system (FSA premium Edition Motility). $5 \mu \mathrm{L}$ of the sperm suspensions were applied and ten random fields from each sample were analyzed. Nine parameters of CASA were analyzed including motility (MOT), curvilinear velocity (VCL), straight-line velocity (VSL), average path velocity (VAP), mean angular displacement (MAD), beat cross-frequency (BCF), amplitude of lateral head displacement (ALH), linearity (LIN), and straightness of path (STR). 


\section{In vitro maturation (IVM) of bovine oocytes}

Domestic cattle ovaries were obtained from a local slaughterhouse. Cumulus-oocyte complexes were aspirated from 2- to 8-mm antral follicles, and then matured in tissue culture medium 199 (Gibco) supplemented with $0.2 \mathrm{mM} \mathrm{Na-pyruvate,} 0.6 \mathrm{mM}$ cysteine, 10\% FBS, $10 \mathrm{ng} / \mathrm{mL}$ EGF, $1 \mathrm{mg} / \mathrm{mL}$ estradiol-17 $\beta$, and $5 \mu \mathrm{g} / \mathrm{mL}$ $\mathrm{FSH}$ at $38.5^{\circ} \mathrm{C}$ in a humidified atmosphere of $5 \% \mathrm{CO}_{2}$ in air for 18 to $22 \mathrm{~h}$.

\section{IVF and in vitro culture (IVC)}

Sorted and unsorted sperm were washed with capacitation-Tyrode's albumin lactate pyruvate (TALPCAP) medium at $1500 \mathrm{rpm}$ for $5 \mathrm{~min}$. The pellet was diluted in $50 \mu \mathrm{L}$ of TALP-CAP medium supplemented with $50 \mu \mathrm{L}$ of heparin $(20 \mathrm{mg} / \mathrm{mL})$ and incubated for $10 \mathrm{~min}$ at $38.5^{\circ} \mathrm{C}$ in a humidified atmosphere of $5 \% \mathrm{CO}_{2}$ in air. The capacitated motile sperm were then diluted in $200 \mu \mathrm{L}$ of TALP-IVF medium to 1 to $2 \times 10^{6}$ sperm/ $\mathrm{mL}$. Matured bovine oocytes were fertilized in $40 \mu \mathrm{L}$ of sperm suspensions at $38.5^{\circ} \mathrm{C}$ in a humidified atmosphere of $5 \% \mathrm{CO}_{2}$ in air for 22 to $24 \mathrm{~h}$.

Embryos were cultured in modified synthetic oviductal fluid (mSOF) for up to 7 days. At day 2 cleavage rate was assessed, and at day 7 blastocyst rates were determined.

\section{Terminal Uridine Nick End Labeling (TUNEL) assay}

TUNEL kit (In Situ Cell Death Detection Kit, TMR red, Roche Diagnostics, Indianapolis, IN) was used to assess the presence of apoptotic cells in blastocysts. The assay was performed according to the previous study by Li et al. (Li et al., 2014) with some modifications. Briefly, at day 7 blastocysts of each group were washed three times in PBS-PVA for 5 min, fixed in 4\% paraformaldehyde for $1 \mathrm{~h}$, and then permeabilized in $1.0 \%$ Triton X-100 for $30 \mathrm{~min}$ at room temperature. Embryos were washed in PBS-PVA three times and incubated in TUNEL reaction medium (Enzyme solution: Label solutions $=1: 9$ ) for $1 \mathrm{~h}$ at $37^{\circ} \mathrm{C}$ in the dark. After reaction, embryos were washed three times in PBS-PVA for $5 \mathrm{~min}$, then incubated with $10 \mu \mathrm{g} / \mathrm{mL}$ of Hoechst 33342 at $38.5^{\circ} \mathrm{C}$ for $5 \mathrm{~min}$ in dark, and mounted in mounting medium with DAPI (Vectashield, Vector Laboratories) at room temperature in the dark. The number of total cells, apoptotic nuclei, and fragmentation were subsequently observed and captured using a fluorescence microscope (TE2000-U, Nikon, Japan). Apoptotic nuclei were stained with both red and blue fluorescence, and nonapoptotic nuclei were stained with blue fluorescence only.

\section{Determination of the sex of embryos}

Nested polymerase chain reaction (PCR) was used to determine the sex of embryos as the method by Yang et al. (Yang et al., 2014) with some modifications. Blastocysts were washed in PBS and then transferred into a $0.2 \mathrm{~mL}$ microcentrifuge tube containing $6 \mu \mathrm{L}$ of distilled water. Blastocysts were lysed by boiling at $100^{\circ} \mathrm{C}$ for $5 \mathrm{~min}$ and freezing in liquid nitrogen for $3 \mathrm{~min}$ prior to mixing with PCR reagents. PCR reaction mixture contained $10 \mu \mathrm{L}$ Premix Ex Taq (Takara Bio), and $0.2 \mu \mathrm{mol} / \mathrm{L}$ of each primer (SRY1 and HBB) were added. The first amplification was carried out for 20 cycles as follows: denaturation at $94^{\circ} \mathrm{C}$ for $45 \mathrm{~s}$, annealing at $61^{\circ} \mathrm{C}$ for $30 \mathrm{~s}$ and extension at $72^{\circ} \mathrm{C}$ for $45 \mathrm{~s}$. Then $4 \mu \mathrm{L}$ of the first PCR product was applied to $10 \mu \mathrm{L}$ Premix Ex Taq containing $0.2 \mu \mathrm{mol} / \mathrm{L}$ of each primer (SRY2 and HBB) (Table 1) and $2 \mu \mathrm{L}$ distilled water for nested amplification (denaturation at $94^{\circ} \mathrm{C}$ for $45 \mathrm{~s}$, annealing at $61^{\circ} \mathrm{C}$ for $30 \mathrm{~s}$ and extension at $72^{\circ} \mathrm{C}$ for $45 \mathrm{~s}$ during 34 cycles). Prior to the each PCR reaction, the samples were heated to $94^{\circ} \mathrm{C}$ for $5 \mathrm{~min}$ to enhance the denaturation of total DNA. At the end of the cycles, the extension step was prolonged for $5 \mathrm{~min}$ to complete the extension of all DNA strands.

Table 1. Genes and primers used in the nested PCR

\begin{tabular}{clc}
\hline Genes & \multicolumn{1}{c}{ Primer sequence (5'-3') } & $\begin{array}{r}\text { Product } \\
\text { size (bp) }\end{array}$ \\
\hline \multirow{2}{*}{ HBB } & $\begin{array}{l}\text { F : TATCCCACTTACAAGGCAGGTT } \\
\text { R : GCAGACAACAGAGAACAAGAATGA }\end{array}$ & 558 \\
\hline \multirow{3}{*}{ SRY1 } & F : CTACTCCCCAACCGTCAGAAC & \multirow{2}{*}{649} \\
& $\mathrm{R}:$ AGCCCAAACCCATCAACCTA & \\
\hline \multirow{3}{*}{ SRY2 } & F : CCAGGGAACTGCTTGGGTA & 219 \\
& $\mathrm{R}:$ TGCTTCTCCACTTAGGCTCAA & \\
\hline
\end{tabular}

PCR products were electrophoretically detected on $1.5 \%$ agarose gel. The product size of SRY and HBB were 219 and 558 bp, respectively. Embryos were considered to be male when both 219 and $558 \mathrm{bp}$ fragments were detected; when only a 558 bp product was visible, the embryos were considered to be female.

\section{Statistical analysis}

For each treatment group, the experiment was repeated at least three times. Data were tested by T test using the SPSS 17.0 software. Data are presented as mean \pm SEM.

\section{RESULTS}

\section{Generation of antibody against $\mathrm{H}-\mathrm{Y}$ antigen}

For separating out male sperm, antibody against $\mathrm{H}-\mathrm{Y}$ antigen was generated. $\mathrm{H}-\mathrm{Y}$ antibody was produced by hybridoma as shown in Fig. 1-A. The concentration was determined by the standard curve of Sandwich ELISA shown in Fig.1-B that the average concentration of generated Moab 12/49 IgM was $13.79 \mu \mathrm{g} / \mathrm{mL}$.

\section{Efficiency of sperm sorting by MACS with anti- body against $\mathrm{H}-\mathrm{Y}$ antigen}

With the H-Y antibody, MACS separated the sperm into two fractions, in which one fraction was attached to the column, and the other fraction was in the flow- 
A

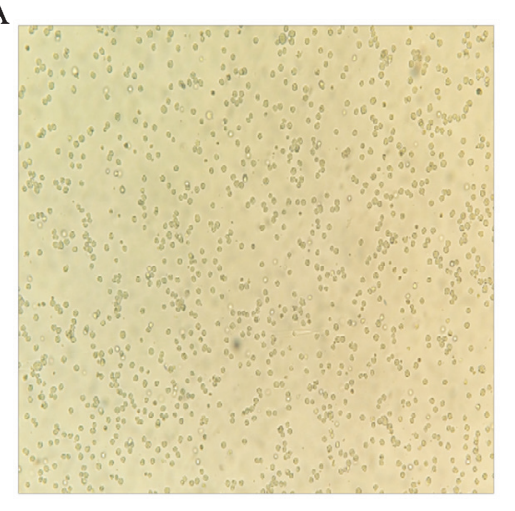

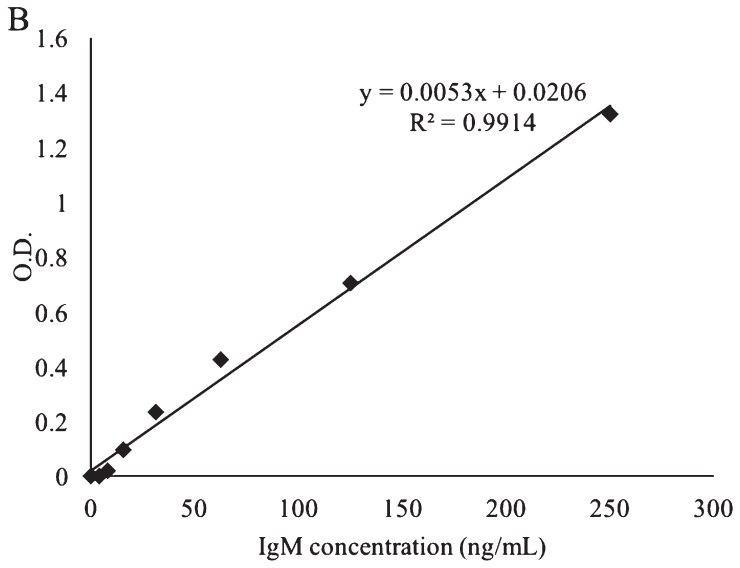

Fig. 1. Antibody production. A: Hybridoma cells used to produce antibody against $H-Y$ antigen $(\times 200)$; B: The standard curve of mouse IgM (B). This experiment was repeated five times independently.

Table 2. Effects of MACS on the distributions of sperm population

\begin{tabular}{ccccc}
\hline Groups & $\begin{array}{c}\text { H-Y antigen negative } \\
(\%, \text { mean } \pm \text { SEM })\end{array}$ & $\begin{array}{c}\text { H-Y antigen positive } \\
(\%, \text { mean } \pm \text { SEM })\end{array}$ & $\begin{array}{c}\text { SRY negative } \\
(\%, \text { mean } \pm \text { SEM })\end{array}$ & $\begin{array}{c}\text { SRY positive } \\
(\%, \text { mean } \pm \text { SEM })\end{array}$ \\
\hline Unsorted & $47.59 \pm 3.90$ & $52.04 \pm 3.79 *$ & $54.28 \pm 1.96$ & $45.31 \pm 1.99 *$ \\
Sorted & $83.98 \pm 1.45^{*}$ & $15.79 \pm 1.34$ & $91.11 \pm 4.28 *$ & $8.48 \pm 4.11$ \\
\hline
\end{tabular}

* Within columns, $\mathrm{P}<0.001$

This experiment was repeated three times independently.

through. The efficiency of MACS was evaluated by FACS with both Moab 12/49 and antibody against SRY protein. The negative population of $\mathrm{H}-\mathrm{Y}$ antigen and SRY protein represented the $\mathrm{X}$-chromosome bearing sperm, and the positive population of them represented the Y-chromosome bearing sperm.
As shown in Table 2, male sperm which expressed $\mathrm{H}-\mathrm{Y}$ and SRY were significantly decreased after MACS (52.04 $\pm 3.79 \%$ vs. $15.79 \pm 1.34 \%$ and $45.31 \pm 1.99 \%$ vs. $8.48 \pm 4.11 \%$, respectively, $\mathrm{P}<0.001$ ) whereas female sperm were significantly increased with negative expression of H-Y antigen and SRY (47.59 $\pm 3.90 \%$ vs. $83.98 \pm$
A

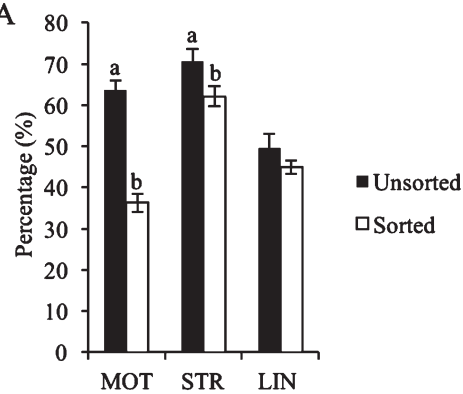

$\mathrm{C}$

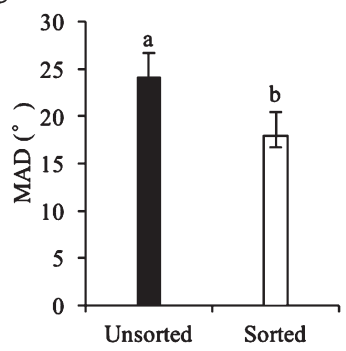

D

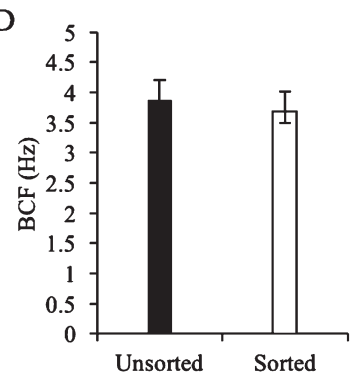

B

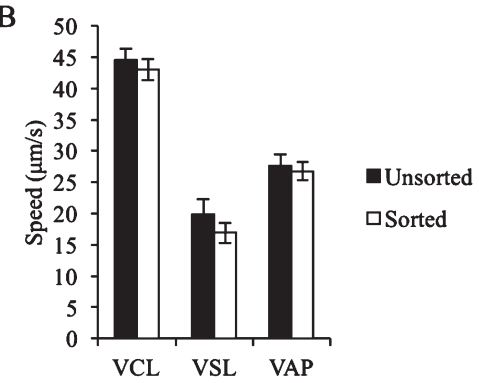

$\mathrm{E}$

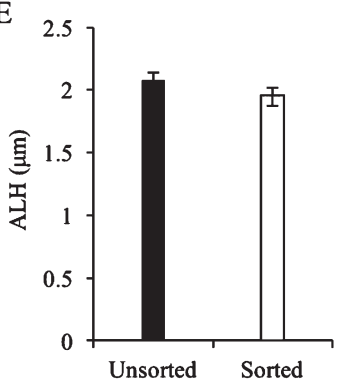

Fig. 2. Effects of MACS on the total motility of sperm. A: MOT, STR and LIN; B: VCL, VSL and VAP; C: MAD; D: $\mathrm{BCF}$ and $\mathrm{E}$ : ALH parameters of unsorted and sorted sperm were analyzed by CASA, ${ }^{\mathrm{a}, \mathrm{b}}$ value means $P<$ 0.05. This experiment was repeated ten times independently. 
Table 3. Effects of MACS on the developments of embryos

\begin{tabular}{cccc}
\hline Groups & $\begin{array}{c}\text { No. of } \\
\text { oocytes }\end{array}$ & $\begin{array}{c}\text { Cleavage rates } \\
(\%, \text { mean } \pm \text { SEM })\end{array}$ & $\begin{array}{c}\text { Blastocyst rates } \\
(\%, \text { mean } \pm \text { SEM })\end{array}$ \\
\hline IVF & 682 & $83.38 \pm 2.29 *$ & $36.25 \pm 2.23^{*}$ \\
MACS-IVF & 633 & $57.98 \pm 2.12$ & $17.70 \pm 1.14$ \\
\hline
\end{tabular}

* Within columns, $\mathrm{P}<0.001$.

This experiment was repeated twelve times independently.
Table 4. Effects of MACS on the quality of embryos

\begin{tabular}{cccc}
\hline Groups & $\begin{array}{c}\text { No. of } \\
\text { blastocysts }\end{array}$ & $\begin{array}{c}\text { Total cell no. } \\
(\%, \text { mean } \pm \text { SEM })\end{array}$ & $\begin{array}{c}\text { Apoptotic cell no. } \\
(\%, \text { mean } \pm \text { SEM })\end{array}$ \\
\hline IVF & 12 & $131.17 \pm 2.69$ & $4.92 \pm 0.62$ \\
MACS-IVF & 12 & $125.83 \pm 1.85$ & $6.08 \pm 0.47$ \\
\hline
\end{tabular}

* Within columns, $\mathrm{P}<0.001$.

This experiment was repeated four times independently.
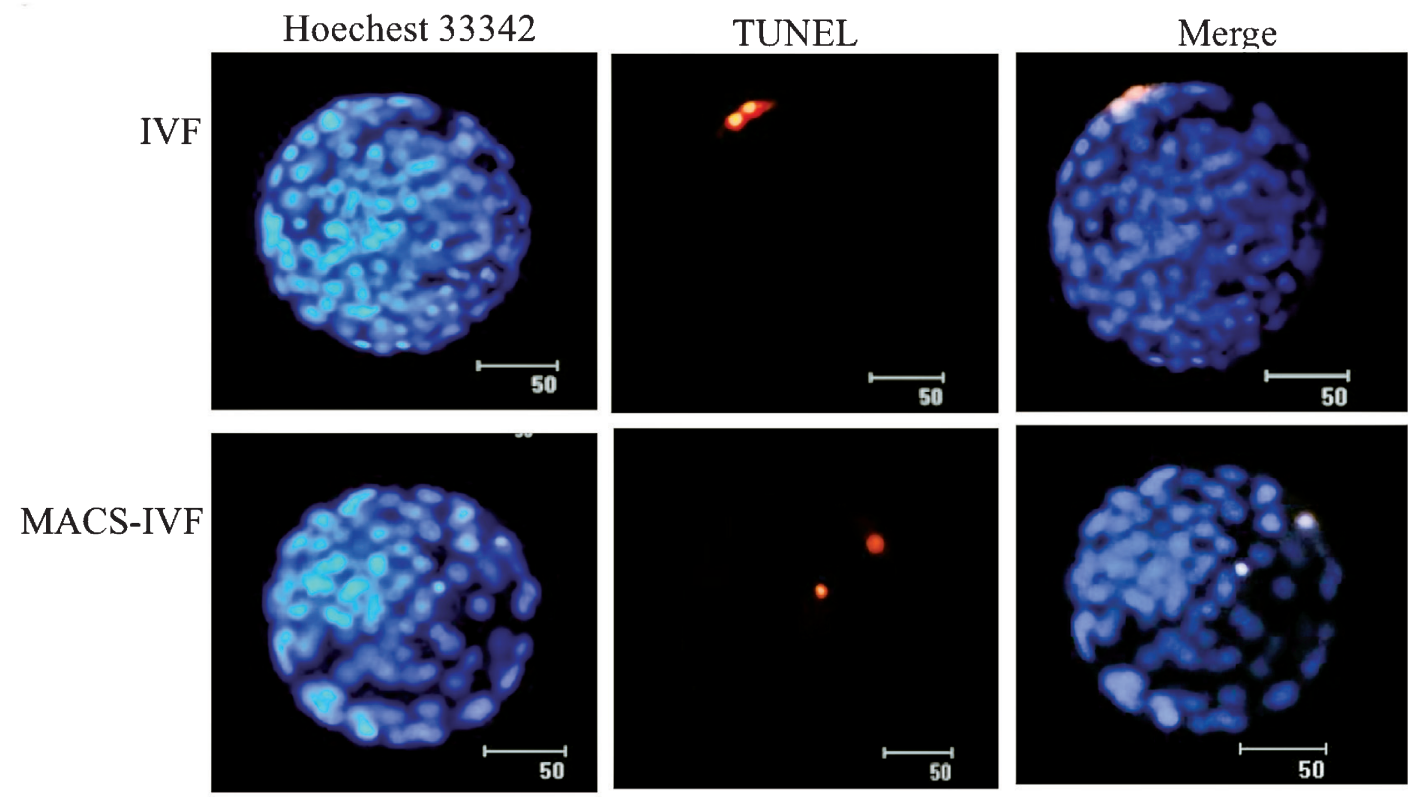

Fig. 3. Apoptotic cell detection in blastocysts. TUNEL staining was used to detect apoptotic cells in blastocysts derived from unsorted and sorted sperm $(\times 200)$. White arrow shows apoptotic nuclear. Bar $=50 \mu \mathrm{m}$. This experiment was repeated four times independently.

$1.45 \%$ and $54.28 \pm 1.96 \%$ vs. $91.11 \pm 4.28 \%$, respectively, $\mathrm{P}<0.001)$.

\section{Effects of MACS on the total motility of sperm}

In order to confirm the effect of MACS on spermquality, the total motilities of sperm were evaluated by CASA. MOT which was represented as the number of motile sperm was significantly reduced by MACS (63.71 \pm $2.23 \%$ vs. $36.28 \pm 2.13 \%, \mathrm{P}<0.05$ ) (Fig. $2-\mathrm{A}$ ). STR and $\mathrm{MAD}$ of sperm swimming with dynamic peculiarity were also significantly changed by MACS (70.53 $\pm 3.09 \%$ vs. $62.13 \pm 2.34 \%$ and $24.22 \pm 2.44^{\circ}$ vs. $17.97 \pm 1.25^{\circ}, \mathrm{P}<$ 0.05) (Fig. 2-A, C). However, other swimming speed and pattern parameters of LIN, VCL, VSL, VAP, BCF and ALH were not significantly influenced by MACS sorting $(49.46 \pm 3.54 \%$ vs. $44.86 \pm 1.66 \%, 44.46 \pm 1.89 \mu \mathrm{m} / \mathrm{s}$ vs. $43.07 \pm 1.68 \mu \mathrm{m} / \mathrm{s}, 19.89 \pm 2.37 \mu \mathrm{m} / \mathrm{s}$ vs. $16.87 \pm 1.53$ $\mu \mathrm{m} / \mathrm{s}, 27.56 \pm 1.93 \mu \mathrm{m} / \mathrm{s}$ vs. $26.75 \pm 1.41 \mu \mathrm{m} / \mathrm{s}, 3.88 \pm$ $0.33 \mathrm{~Hz}$ vs. $3.69 \pm 0.20 \mathrm{~Hz}, 2.08 \pm 0.06 \mu \mathrm{m}$ vs. $1.96 \pm$ $0.09 \mu \mathrm{m}$, respectively) (Fig. $2-\mathrm{A}, \mathrm{B}, \mathrm{D}, \mathrm{E})$.

The fertility of sorted sperm and embryo development

After MACS H-Y antigen negative sperm were used to fertilize bovine oocytes. The cleavage rate of embryos derived from sorted sperm was significantly lower than those of embryos fertilized with unsorted sperm (Table $3 ; 83.38 \pm 2.29 \%$ vs. $57.98 \pm 2.12 \%, \mathrm{P}<0.001)$. The rate of blastocyst formation was also significantly lower in in vitro cultured embryos which were fertilized with sorted sperm compared to those with unsorted sperms (Table $3 ; 36.25 \pm 2.23 \%$ vs. $17.70 \pm 1.14 \%, \mathrm{P}<0.001)$.

\section{Effects of sorted sperm on embryo quality}

Table 4 and Fig. 3 show the total cell number and apoptotic cell number of blastocysts produced with both unsorted and sorted sperm. The results show that no significant difference was detected between those two groups of embryos regarding the total cell number and apoptotic cell number $(131.17 \pm 2.69 \%$ vs. $125.83 \pm$ $1.85 \%$ and $4.92 \pm 0.62 \%$ vs. $6.08 \pm 0.47 \%$, respectively).

\section{The sex of embryos derived from sorted sperm by} MACS

The sex of blastocysts was confirmed by genotyping for SRY and HBB genes (Fig. 4 and Table 5). The targets yielding products of both 558 bp and 219 bp were considered to be male blastocysts (Fig. 4, lanes 6 and 7), and targets yielding only a product of $558 \mathrm{bp}$ were presumed to be female blastocysts (Fig. 4, the lanes 2, 3, 4, 


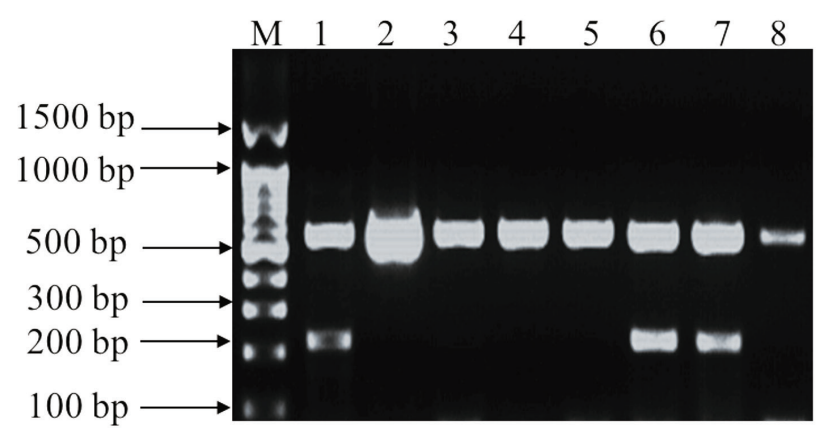

Fig. 4. Agarose gel electrophoresis of nested PCR. Lane 1: male blood sample. Lane 2: female blood sample. Lane 3-8: blastocysts.

Table 5. Effects of MACS on the sex of embryos

\begin{tabular}{cccc}
\hline Group & $\begin{array}{c}\text { No. of } \\
\text { blastocysts }\end{array}$ & $\begin{array}{c}\text { Percentage of } \\
\text { female } \\
(\%, \text { mean } \pm \text { SEM) }\end{array}$ & $\begin{array}{c}\text { Percentage of } \\
\text { male (\%, mean } \pm \\
\text { SEM })\end{array}$ \\
\hline IVF & 72 & $48.36 \pm 2.73$ & $49.42 \pm 3.24^{*}$ \\
MACS-IVF & 69 & $83.64 \pm 4.48^{*}$ & $15.77 \pm 4.26$ \\
\hline
\end{tabular}

* Within columns, $\mathrm{P}<0.001$.

This experiment was repeated nine times independently.

5, and 8). The rate of females was significantly increased in embryos which were fertilized with sperm sorted by MACS compared with the embryos which were fertilized with unsorted sperm (83.64 $\pm 4.48 \%$ vs. $48.36 \pm 2.73 \%$, $\mathrm{P}<0.001$ ) (Table 5).

\section{DISCUSSION}

The sex of animals is often related to the profits of the livestock industry (Espinosa-Cervantes et al., 2013) including sex pre-selected offspring (Abdel-Azim et al., 2007) because of the financial advantages of a certain sex. The pre-selecting sex of sperm has been approached to produce the offspring with targeted sex. In previous studies, it has been shown that sorting by flow cytometry could affect sperm DNA integrity (BoeHansena et al., 2005) and ultrastructural features (Palma et al., 2008) that reduced the fertility of sperm and embryo developmental competence significantly after IVF (Wilson et al., 2006; Jo et al., 2014). For example, Jo et al. (2014) demonstrated that the rates of cleavage and blastocyst formation were decreased to $43.6 \%$ and $9 \%$, when sperm sorted by flow cytometry were used to fertilize oocytes in vitro. In contrast, MACS is a relatively stable method to select sperm (Glander et al., 2002). MACS has been used as a preparation technique in ART because it is an inexpensive and readily available approach to yield motile, viable, and morphologically normal sperm (Aziz et al., 2007; Said et al., 2006). To the best of our knowledge, this is the first study to generate IVF embryos with sperm sex-sorted by MACS.

The minor histocompatibility antigen $\mathrm{H}-\mathrm{Y}$ is coded for by the Y-chromosome, and is expressed on cells of male individuals (Simpson et al., 1987). Peter et al.
(Hendriksen et al., 1993) reported that anti-H-Y antigen monoclonal antibodies were capable to bind 20 to $50 \%$ of the bovine and porcine sperm. Ali et al. (Ali et al., 1990) also suggested that Moab 12-49 could bind to about $50 \%$ of the sperm, which is mainly restricted to Ychromosome bearing sperm.

In order to collect male sperm to separate female sperm, Moab 12/49 were used in the MACS. In the results, sorted sperm contained significantly decreased $\mathrm{H}-\mathrm{Y}$ antigen and SRY positive fractions indicating that the $\mathrm{X}$-chromosome bearing sperm were effectively enriched by MACS. The result also corresponded with the previous research (Bennett et al., 1973; Zavos et al., 1983; Ali et al., 1990; Peter et al., 1993). In addition Li et al. (Li et al., 2011) have reported that the SRY transcripts and protein are present in bovine sperm that could be also used as a good indicator of Y-chromosome bearing sperm.

For producing offspring with targeted sex by sorted sperm it is important to maintain the fertility of sperm after sorting. The fertility of sperm can be estimated based on the morphology and motility of sperm in vitro. The motility of sperm is typically measured based on straightness, progressive trajectories, curvilinearity, and amplitude of lateral displacement (Tardif et al., 1997; Suh et al., 2005). In the previous studies flow cytometry sexing under high pressure significantly deteriorated the quality of sperm including curvilinearity of trajectory, the amplitude of lateral head displacement, the swimming speed and patterns, and beat frequency (Suh et al., 2005; Penfold et al., 1998). In the present study, MACS procedure affected negatively the number of motile sperm and swimming patterns. However, MACS did not affect other kinetic parameters. Moreover, the sperm still maintained fertility after MACS as shown by successful recovery of fertilized oocytes in vitro.

Fugger et al. (1998) suggested that embryos with the higher number of total cells and fewer apoptotic cells would result in improved implantation and calving. Therefore the numbers of total cells and apoptotic cells have been widely used as an indicator for embryo quality. In this study, no differences were found in either total or apoptotic cell numbers between blastocysts derived from unsorted and sorted sperm. Therefore, MACS-sorted sperm did not influence blastocyst quality. In addition the rate of female embryos was significantly increased when MACS-sorted sperm were used in fertilization. Flow cytometry has been used as the routine procedure to separate the sex of sperm, and the efficiency of flow cytometry to sort sperm to produce female blastocysts has been known to be about 80\% (BermejoAlvarez et al., 2008). In comparison with flow cytometry the efficiency of MACS to sort sperm to produce female blastocysts is similar.

In conclusions, MACS using the antibody against $\mathrm{H}-\mathrm{Y}$ antigen effectively enriched $\mathrm{X}$-chromosome bearing sperm by avoiding significant damage on sperm motility. The MACS-sorted sperm still maintained their fertility that would be used to produce offspring with targeted sex that contributes to the benefit of animal industry and to conserve sex-related traits or genes. 


\section{AUTHOR CONTRIBUSIONS}

Lili Zhuang conceived of the presented idea, designed the experiment, carried out the experiment, and wrote the manuscript.

Ju Lan Chun conceived of the presented idea, carried out the experiment, developed the theory, and wrote the manuscript.

Junbo $\mathrm{Wu}$ contributed to sample preparation and performed the computations.

Ji Hye Lee, Eun Young Kim, Bo Myoung Lee contributed to sample preparation and performed the experiment.

Nobuhiko Yamaichi conceived the original idea, discussed the results, and contributed to the final version of the manuscript.

Min Kyu Kim conceived the original idea, discussed the results, supervised the project, and contributed to the final version of the manuscript.

\section{ACKNOWLEDGEMENT}

This study was financially supported by research fund of Chungnam National University at Republic of Korea in 2014.

\section{REFERENCES}

Abdel-Azim, G. and S. Schnell 2007 Genetic impacts of using female-sorted semen in commercial and nucleus herds. $J$ Dairy Sci 90: 1554-1593

Ali, J. I., F. E. Eldridge, G. C. Koo and B. D. Schanbacher 1990 Enrichment of bovine $\mathrm{X}$ and $\mathrm{Y}$ chromosome-bearing sperm with monoclonal H-Y antibody-fluorescence-activated cell sorter. Arch Andrology 24: 235-245

Aziz, N., T. Said, U. Paasch and A. Agarwal 2007 The relationship between human sperm apoptosis, morphology and the sperm deformity index. Hum Reprod 22: 1413-1419

Bennett, D. and E. A. Boyse 1973 Sex ratio in progeny of mice inseminated with sperm treated with $\mathrm{H}-\mathrm{Y}$ antiserum. Nature 246: 308-309

Bermejo-Alvarez, P., D. Rizos, D. Rath, P. Lonergan and A. Gutiérrez-Adán 2008 Can bovine in vitro-matured oocytes selectively process X- or Y-sorted sperm differentially? Biol Reprod 79: $594-597$

Blondin, P., M. Beaulieu, V. Fournier, N. Morin, L. Crawford, P. Madan and W. A. King 2009 Analysis of bovine sexed sperm for IVF from sorting to the embryo. Theriogenology 71: 30-38

Boe-Hansena, G. B., I. D. Morrisb, A. K. Ersbølla, T. Grevea and P. Christensen 2005 DNA integrity in sexed bull sperm assessed by neutral Comet assay and sperm chromatin structure assay. Theriogenology 63: 1789-1802

Ericsson, R. J., C. N. Langevin and M. Nishino 1973 Isolation of fractions rich in human Y sperm. Nature 246: 421-424

Espinosa-Cervantes, R. and A. Córdova-Izquierdo 2013 Sexing sperm of domestic animals. Trop Anim Health Prod 45: 1-8

Fugger, E. F., S. H. Black, K. Keyvanfar and J. D. Schulman 1998 Births of normal daughters after MicroSort sperm separation and intrauterine insemination, in-vitro fertilization, or intracytoplasmic sperm injection. Hum Reprod 13: 2367-2370

Gil, M., V. Sar-Shalom, Y. Melendez Sivira, R. Carreras and M. A. Checa 2013 Sperm selection using magnetic activated cell sorting (MACS) in assisted reproduction: a systematic review and meta-analysis. J Assist Reprod Genet 30: 479-485

Glander, H. J., J. Schiller, R. Suss, U. Paasch, S. Grunewald and J.
Arnhold 2002 Deterioration of spermatozoal plasma membrane is associated with an increase of sperm lyso-phosphatidylcholines. Andrologia 34: 360-366

Goldberg, E. H., E. A. Boyse, D. Bennett, M. Scheid and E. A. Carswell 1971 Serological demonstration of H-Y (male) antigen on mouse sperm. Nature 232: 478-480

Hendriksen, P. J., M. Tieman, T. Van Der Lende and L. A. Johnson 1993 Binding of anti-H-Y monoclonal antibodies to separated $\mathrm{X}$ and $\mathrm{Y}$ chromosome bearing porcine and bovine sperm. $\mathrm{Mol}$ Reprod Dev 35: 189-196

Jain, A., H. M Yathish, J. Tripti and A. Sharma 2011 Efficient production of sexed semen by flow cytometry: A Review. Agri Review 32: 36-45

Jo, H. T., J. I. Bang, S. S. Kim, B. H. Choi, J. I. Jin, H. L. Kim, I. S. Jung, T. K. Suh, N. Ghanem, Z. Wang and I. K. Kong 2014 Production of female bovine embryos with sex-sorted sperm using intracytoplasmic sperm injection: Efficiency and in vitro developmental competence. Theriogenology 81: 675-682

Johnson, L. A. 2000 Sexing mammalian sperm for production of offspring: the state-of-the-art. Anim Reprod Sci 61: 93-107

Li, X. X, K. B. Lee, J. H. Lee, K. J. Kim, E. Y. Kim, K. W Han, K. S. Park, J. Yu and M. K Kim 2014 Glutathione and cysteine enhance porcine preimplantation embryo development in vitro after intracytoplasmic sperm injection. Theriogenology $\mathbf{8 1}$ 309-314

Li, C., Y. F. Sun, K. Yi, C. J. Li, X. L. Zhu, L. Chen and X. Zhou 2011 Detection of the SRY transcript and protein in bovine ejaculated spermatozoa. Asian-Aust J Anim Sci 24: 13581364

Maxwell, W. M. C., G. Evans, F. K. Hollinshead, R. Bathgate, S. P. de Graaf, B. M. Eriksson, L. Gillan, K. M. Morton and J. K. O'Brien 2004 Integration of sperm sexing technology into the ART toolbox. Anim Reprod Sci 82-83: 79-95

Palma, G. A., N. S. Olivier, Ch. Neumuller and F. Sinowatz 2008 Effects of sex-sorted spermatozoa on the efficiency of in vitro fertilization and ultrastructure of in vitro produced bovine blastocysts. Anat Histol Embryol 37: 67-73

Penfold, L. M., C. Holt, W. V. Holt, G. R. Welch, D. G. Cran and L. A. Johnson 1998 Comparative Motility of X and Y ChromosomeBearing Bovine Sperm Separated on the Basis of DNA Content by Flow Sorting. Mol Reprod Dev 50: 323-332

Peter, A. T., P. P. Jones and J. P. Robison 1993 Fractionation of bovine spermatozoa for sex selection: a rapid immunomagnetic technique to remove spermatozoa that contain the $\mathrm{H}-\mathrm{Y}$ antigen. Theriogenology 40: 1177-1185

Peter, B. and C. G. Vosa 1970 The Y chromosome in human spermatozoa. Nature 226: 961-962

Rath, D. and L. A. Johnson 2008 Application and commercialization of flow cytometrically sex-sorted semen. Reprod Domest Anim 2: 338-346

Said, T. M., A. Agarwal, S. Grunewald, M. Rasch, H. J. Glander and U. Paasch 2006 Evaluation of sperm recovery following annexin V magnetic-activated cell sorting separation. Reprod Biomed Online 13: 336-339

Said, T. M., A. Agarwal, M. Zborowski, S. Grunewald, H. J. Glander and U. Paasch 2008 Utility of magnetic cell separation as a molecular sperm preparation technique. J Andro 29: 134-142

Seidel Jr, G. E. 2007 Overview of sexing sperm. Theriogenology 68: $443-446$

Simpson, E., P. Chandler, E. Goulmy, C. M. Disteche, M. A. Ferguson-Smith and D. C. Page 1987 Separation of the genetic loci for the $\mathrm{H}-\mathrm{Y}$ antigen and for testis determination on human $\mathrm{Y}$ chromosome. Nature 326: 876-878

Penfold, L. M., C. Holt, W. V. Holt, G. R. Welch, D. G. Cran and L. A. Johnson 1998 Comparative Motility of X and Y ChromosomeBearing Bovine Sperm Separated on the Basis of DNA Content by Flow Sorting. Mol Reprod Dev 50: 323-327

Tardif, A. L., P. B. Farrell, V. Trouern-Trend and R. H. Foote 1997 Computer-assisted sperm analysis for assessing initial semen quality and changes during storage at $5^{\circ} \mathrm{C}$. J Dairy Sci 80: 1606-1612

Vermes, I., C. Haanen, H. Steffens-Nakken and C. Reutelingsperger 
2005 A novel assay for apoptosis: flow cytometric detection of phosphatidylserine expression of early apoptotic cells using fluorescein labeled Annexin V. J Immunol Methods 184: 39-51

Wilson, R. D., P. M. Fricke, M. L. Leibfried-Rutledge, J. J. Rutledge, C. M. Penfield and K. A. Weigel 2006 In vitro production of bovine embryos using sex-sorted sperm. Theriogenology $\mathbf{6 5}$ : $1007-1115$
Yang, W. C., L. Sang, Y. Xiao, H. L. Zhang, K. Q. Tang and L. G. Yang 2014 Tentative identification of sex-specific antibodies and their application for screening bovine sperm proteins for sex-specificity. Mol Biol Rep 41: 217-223

Zavos, P. M. 1983 Preconception sex determination via intra-vaginal administration of $\mathrm{H}-\mathrm{Y}$ antisera in rabbits. Theriogenology 20: $235-240$ 